\title{
A simple eyelid conditioning masking task and its effect on differential conditioning'
}

LEONARD E. ROSS, SUSAN M. WILCOX AND MELANIE J. MAYER

UNIVERSITY OF WISCONSIN

Differential eyelid conditioning performance to complex (color and form) stimuli was compared under standard-instructional and masking-task conditions. Although excellent differential conditioning was obtained with standard instructions, there was very little differential responding when a simple time estimation masking task was employed.

Recently there has been interest in the effect of requiring Ss in eyelid conditioning studies to perform a "masking" or "cover" task, a procedure which presumably changes the cognitive or inhibitory set of the S. Marked differences have been reported with the use of a masking task, including much slower extinction (Spence, 1963; Spence, Homzie, \& Rutledge, 1964), and the elimination of both the partial reinforcement effect in extinction and the partial reinforcement decrement normally found in acquisition (Spence \& Platt, 1967).

While the cognitive set interpretation of these effects is plausible, the masking task previously used introduces new stimuli which may unnecessarily complicate the conditioning situation. The typical masking task has taken the form of a probability learning game in which S predicts which of two small lamps will light. A signal lamp is presented for 2 sec immediately prior to CS onset, and during this interval $S$ is required to press one of two pushbuttons to indicate his prediction. Following the trial, one of the small lamps is 1it. It is not known if these additional stimuli have an effect, per se, on conditioning and extinction phenomena.

The present preliminary study reports a simplified masking procedure which avoids the introduction of new stimuli but which retains the critical feature of masking the true purpose of the study. This new masking task involves informing the $S$ that the study is concerned with time estimation, the S's task being to push two buttons, one $2 \mathrm{sec}$ and the other $5 \mathrm{sec}$ after the termination of the CS. The effects of this masking procedure were investigated in a differential conditioning paradigm, since cognitive factors might be expected to affect differential responding in situations where two or more cues and reinforcement contingencies are involved. Relevant to this possibility, recent work at Wisconsin indicates that the differential eyelid conditioning performance of normal and retarded children is poorer than that of college students, a finding which may reflect a cognitive facilitation of the differential responding of college students.

\section{Method}

The Ss were 32 college students attending summer session. Half served for class "points" and half were paid for their participation. All Ss were tested with Dvorine color perception testing charts before the conditioning session.

The CS stimuli were presented by an Industrial Electronics readout unit located $47 \mathrm{in}$. in front of and 12 in. above the eye level of $S$. On each trial a single 2 in. white figure appeared on a $3 \times 5 \mathrm{in}$. colored background. During the experimental session, combinations of two colors and two forms were displayed to each $S$ with one dimension, either color or form, relevant (one value, CSt, always reinforced; the other, CS-, never reinforced) and the remaining dimension irrelevant (each value appearing $50 \%$ of the time with CSt and $50 \%$ of the time with CS-).

The interstimulus interval was $800 \mathrm{msec}$, the intertrial interval was 15,20 , or $25 \mathrm{sec}$ with a mean of $20 \mathrm{sec}$, and the US was a $100 \mathrm{msec}, .75 \mathrm{psi}$ air puff. The CS and US terminated together. White noise was presented to the $S$ through Sharpe HA-10 earphones with an intensity which had been matched to a white noise of $65 \mathrm{~dB}$ SPL presented by a speaker.

Half of the Ss were given the masking task instructions and half standard instructions. Number of paid and point Ss, relevant dimension, and CS+ were balanced within each task-condition group.

Instructions given to the masking task group included statements that, "This is an experiment involving time estimation. We are interested in how you estimate various time intervals when distracting stimuli are presented...F For your time estimation task, all you have to do is sit quietly and look straight ahead at the screen. At varlous times lights will appear in front of you, along with other distractors. Your task is to judge time intervals after the lights go off. After you think $2 \mathrm{sec}$ has gone by, press the button on the right arm of the chair. After you think 5 sec have gone by, press the button on the left arm of the chair." After several Ss had been run, masking instructions were modified to include asking $S$ to remove his watch for the session. No masking task Ss were told that the purpose of the experiment was to find out the Ss' "reactions to certain lights."

Each $\mathrm{S}$ was given four trials, each with one of the four cue combinations but no US, followed by one USalone trial. The $S$ was then told, "Now we are ready to begin," and 80 trials were given with CS+ and CSpresented according to three tandem Gellermann orders. 


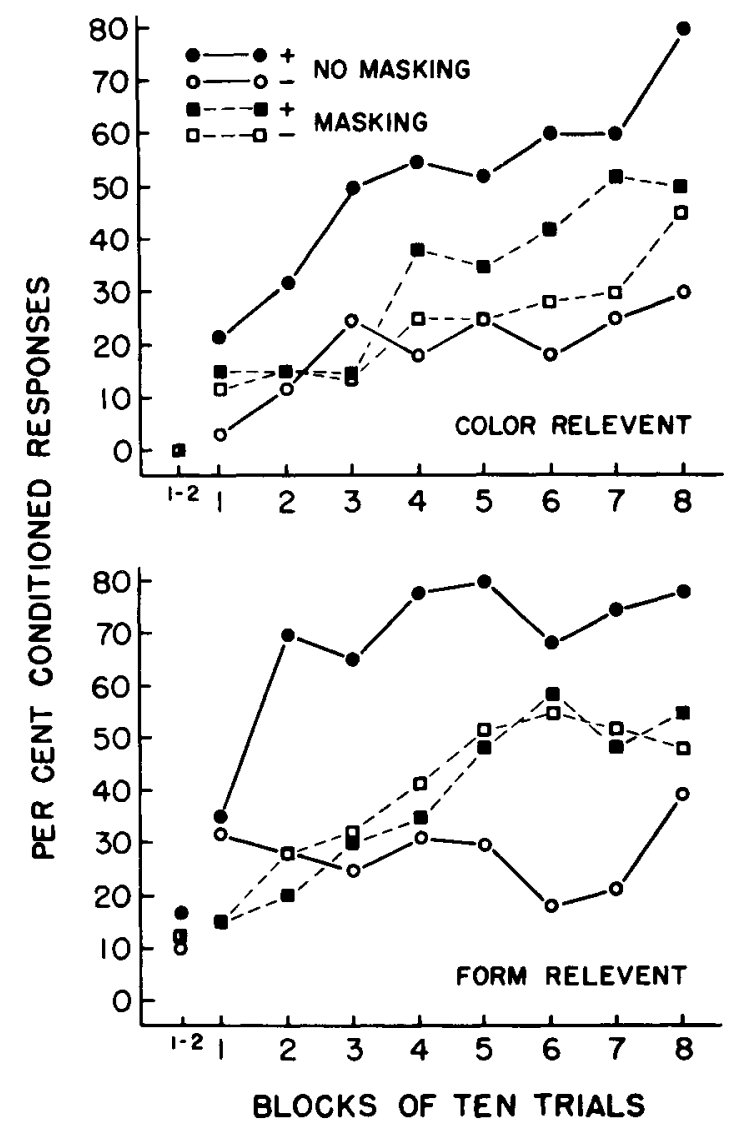

Fig. 1. Conditioning curves for relevant dimensional and masking-task conditions, $\mathrm{N}=8$ /group.

\section{Results and Discussion}

A $2 \mathrm{~mm}$ or greater pen deflection in the interval from 200-800 msec after CS onset was scored as a CR. Figure 1 presents conditioning curves for each of the relevant dimension conditions under both the masking task and the no masking task conditions. An analysis of variance of CS+-CS- difference scores over the last four blocks of 10 trials found the masking task-no masking task effect significant at the .005 level $(F=12.23, \mathrm{df}=1 / 28)$. Neither the relevant dimension nor the dimension by task condition interaction was significant ( $F<1$ ). Although it appears that there may have been differential responding to the CS+ and CS- by the color relevant masking task group, a t test failed to find a significant difference over the last four blocks of trials $(t=1.69, d f=7, p>.10)$. Similar comparisons for the no masking task groups found significant differences at the .01 and .02 levels, respectively, for form and color relevant groups.

It was thought that the masking task used in this study might have had its effects by reducing the number of "voluntary form" responders. Accordingly, the data was scored by the derivative amplitude (slope) criteria suggested by Hartman \& Ross (1961). It was found, however, that only two no masking task Ss and one masking task $S$ met the voluntary $S$ criterion and an analysis of difference scores with voluntary Ss removed also found a significant masking-no masking difference $(F=11.43$, df $=1 / 25, p<.005)$.

The data from this study suggest that the superior differential conditioning performance under the no masking condition was dependent upon the S's involvement in the problem. While the use of stimuli varying in two dimensions may have increased S's tendency to become cognitively involved, such factors may also operate in differential conditioning studies involving unidimensional stimuli. The effectiveness of the time estimation instructions in this situation suggests that further investigation of this masking task would be fruitful, since it does not introduce new stimuli just before the onset of the trial and is simple to instrument and use.

\section{References}

HARTMAN, T. F., \& ROSS, L. E. An alternative criterion for the elimination of "voluntary" responses in eyelid conditioning. J. exp. Psychol, 1961, 61, 334-338.

SPENCE, K. W. Cognitive factors in the extinction of the conditioned eyelid response in humans. Science, 1963, 140, 1224-1225.

SPENCE, K. W., HOMZIE, M. J., \& RUTLEDGE, E. F. Extinction of the human eyelid $\mathrm{CR}$ as a function of the discriminability of the change from acquisition to extinction. J. exp. Psychol, 1964, 68, 545-552.

SPENCE, K. W., \& PLATT, J. R. Effects of partial reinforcement on acquisition and extinction of the conditioned eyeblink in a masking situation. J. exp. Psychol, 1967, 74, 259-263.

\section{Note}

1. Supported by PHS Grant MH 10235 and PHS Training Program HD 00117. 